\title{
A CASE OF OSSIFICATION OF THE MUSCLES.
}

By Wrlliax Skivier, M.B., Lond., \&c., of Manchester, ENG.

Tris singular case is that of a boy, 13 jears old, the second of eight children of healthy parents. He was quite healthy until about six years ago, when a swelling was noticed at the back of his neck, without any known causc. "This disappeared in about a week, another being observed behind the right shoulder. Three weeks later the arms gradually became so stiff that for about three months they werc firmly fixed, and the boy was obliged to be fed. He, however, somewhat improved in this respect, and for some time past has been able to feed himself, although with much difficulty. From that time to the present, various lumps have formed in different parts of the body, these being principally about the spine and chest; and whenever the boy receives a blow it is followed by a similar swelling. Their appearance is preceded by pain, tenderness, and slight fererishness.

"The condition of the boy at the present time is as follows:He stoops somewhat; the shoulders are contracted; there is no motion in the right joint, and very little in the left; the arms cannot be extended, and are in a semi-flexed position, crossing the abdomen. The chest is narrow, very much flattened on either side, at the junction of the ribs with their cartilages, and these somewhat nodulated. There is no morement of the chest with respiration. The abdomen and lower extremities are well developed, the latter straight, without signs of rickets. There is no movement in the spine, and the scapulæ are fixed; the buttocks and lower extremities present nothing abnormal. On manipulation, a number of small projections are felt over the ribs. The right pectoral muscles are completely fixed, and converted into a hard, bony substancc. The lower edge of the greater can be traced from a nodule below the right nipple, crossing the axilla, forming a hard and sharp ridge, which is continued into the biceps as far as its insertion into the radius; a number of little bony nodules may be felt along its course, and a long irregular splinter of bone behind it. The muscles of the forearm do not seem to be affected. On the left side there is much the same condition of things as on the right, except that the muscles of the forearm are here beginning to be more or less fixed, and there exists a long, sharp, bony riuge from the outer condyle to about two thirds of the length of the forearm.

"Posteriorly, on the left side of the neck, and apparently in the trapezius immediately after its origin from the occiput, is a projection of hard, bony substance, about the size and shape of a pigeon's egg. Lower down, between the angle of the scapula and the spine, is a large, hard, irregular mass. In the dorsal region, at about the tenth and eleventh vertebræ, where the trapezius takes its rise, and apparently formed in the angle of this muscle 
of the left side, is another hard and somewhat morable mass. It is angular in shape, and extends upward on the side of the spine about one and a half inches, and outward and upward, in the lower fold of the muscle, about one inch. Moreorer, in tracing the lower edge of this muscle to its attachment to the scapula some hardness is felt. and here and there sharp spicula of bone-like matter. On the right side, about two inches below the lower angle of the scapula, is another hard and irregular projection, alout the size of a large egg, the last which has made its appearance; apparently it is incorporated in the lower edge of the latissimus dorsi. In the lumbar region, on each side, hard, bony plates occupy both spaces. The buttocks and lower extremities are quite free from diseasc, excepting one small nodule, about the size of a common nut, situated over the right os calcis, at the insertion of the tendo Achillis."

This boy exlibited no other structural or functional abnormity. He had taken iodide of potassiun, but without any beneficial effect.

"Examples of this peculiar disease may be found recorded by Mr. C. Hawkins in the Medical Guzette, 1843 and 1844; by Dr. Rogers in vol. xiii. of the Amcrican Journal of the Med. Sciences; by Dr. Wilkinson in the Medical Gazette for $18 \pm 6$; by Dr. Testelin in the Guzette Médicale de Paris for 1839. In the museum of the Royal College of Surgcons of England there is a fine specimen of the disease, the description of which is given in the Pathological Caulogue, vol. v., p. 138, No. 3367."-Medical Times and Guzetle, April 20, 1861.

\section{THE BOSTON MEDICAL AND SURGICAL JOURNAL.}

\section{BOSTON: THURSDAY, JULY 18, 1861.}

ThE following letter from $\mathrm{Dr}$. MARTiN contains interesting information with regard to the appearance of variolous disease among the troops at Fortress Monroe. Its statements fully confirm the impression which we expressed in our editorial of the 4 th inst., that the newspapers were making a great deal out of what was, in fact, not a very serious inatter. We print the letter as it is written, reserving to ourselves the privilege of adding a few comments at its conclusion.

Caxp Butief, Newport's News, Dept. op Vibgisia,
July 10th, 1861.

Messrs. Editors,-I notice in the number of your Joursal of July 4th (receired yesterday), an editorial in regard to the vaccination of the troops from Massachusetts. The article referred to deals in such phrases as "We certainly thIsk, so far as we are acquainted with facts," \&c.; "We have no reason to doubt," and "We have little doubt," \&c. \&c. As there ip no internal exidence that the editorial alluded to 